\title{
Sind Besprechungen Arbeitszeit?
}

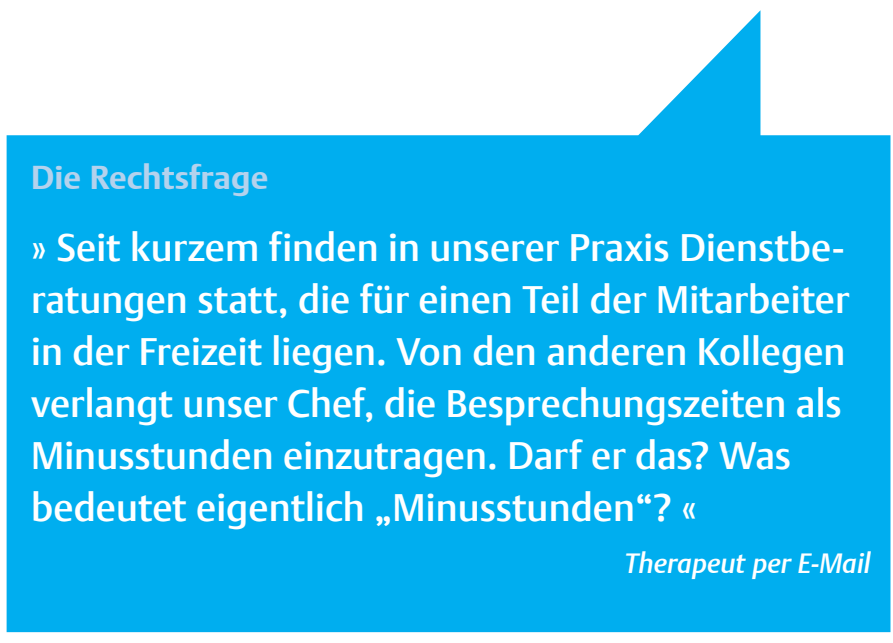

\section{Die Antwort unseres Experten}

Grundsätzlich gilt: Arbeitszeit ist die Zeit, in der ein Arbeitnehmer Leistungen erbringt, für die er vom Arbeitgeber eine Vergütung verlangen kann. Welche Arbeit wann wie zu erledigen ist, kann der Chef im Rahmen seines sogenannten Direktionsrechts bestimmen. Dabei ist er an vertragliche Vereinbarungen, Tarifverträge und Gesetze gebunden und muss „billiges Ermessen“ ausüben. Bei der Dienstplangestaltung muss er also die berechtigten Interessen der Arbeitnehmer berücksichtigen, ist jedoch nicht verpflichtet, allen Wünschen nachzukommen.

Während der Arbeitszeit müssen Sie als Arbeitnehmer die vertraglich festgelegte Leistung erbringen. Umgekehrt haben Sie Freizeit, wenn Sie frei über Ihre Zeit verfügen können. Dazu zählen auch Pausen, sofern zu Beginn der Pause feststeht, wie lange sie dauert und dass der Arbeitnehmer in dieser Zeit nicht zur Arbeit herangezogen werden darf. Müssen Sie sich an einem bestimmten Ort bereithalten, um bei Bedarf zu arbeiten, warten Sie also zum
Beispiel in der Praxis auf einen Patienten, handelt es sich um Arbeitszeit. Bei Dienstberatungen, die Ihr Arbeitgeber anweist, müssen Sie sich an dem von ihm bestimmten Ort aufhalten und können auch nicht frei über Ihre Zeit verfügen. Daher sind derartige Besprechungen Arbeitszeit. Treffen sich jedoch Mitarbeiter außerhalb der Arbeitszeit und besprechen dienstliche Belange, ohne dass dies vom Arbeitgeber angewiesen wurde, gilt das als Freizeit.

Im Ergebnis heißt das, dass der Arbeitgeber die Dienstberatung für Mitarbeiter außerhalb deren regulärer Arbeitszeit legen darf. Er muss diese Zeit aber als Arbeitszeit vergüten. Minusstunden kann er für Dienstberatungen nicht schreiben, und bei der zeitlichen Lage der Besprechung muss er billiges Ermessen wahren.

Zu den Minusstunden: Im Arbeitsvertrag ist in der Regel vereinbart, wie viel Arbeitszeit Sie erbringen müssen. Ist nicht genug Arbeit vorhanden, obwohl Sie zur Verfügung stehen, muss der Arbeitgeber trotzdem die vereinbarte Vergütung bzw. die vereinbarten Stunden bezahlen. Allerdings kann man ein Arbeitszeitkonto einführen, in dem man grundsätzlich die Mehrstunden registriert. Das ist Arbeitszeit, die bereits erbracht wurde, aber erst später bezahlt oder durch bezahlte Freistellung abgegolten werden soll. Wer Überstunden abfeiert, zieht diese vom Arbeitszeitguthaben ab. Möglich ist aber auch die Vereinbarung, dass das Arbeitszeitkonto ein „Minus“ aufweisen kann. Hier bezahlt der Arbeitgeber Arbeitszeit, die noch nicht geleistet wurde. Das Minuskonto kann man dann später mit Mehrarbeit ausgleichen.

Karsten Bossow

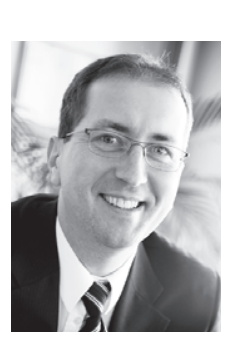

Karsten Bossow ist seit 1999 Rechtsanwalt. Seit 2003 ist er Fachanwalt für Arbeitsrecht und seit 2010 für Medizinrecht. 